\title{
Potential Linkages Between Social Capital, Flood Risk Perceptions, and Self-Efficacy
}

\author{
Paul Hudson $^{1}$ (D) Liselotte Hagedoorn $^{2}$ (D) Philip Bubeck ${ }^{1}$ (D)
}

Published online: 16 March 2020

(C) The Author(s) 2020

\begin{abstract}
A growing focus is being placed on both individuals and communities to adapt to flooding as part of the Sendai Framework for Disaster Risk Reduction 2015-2030. Adaptation to flooding requires sufficient social capital (linkages between members of society), risk perceptions (understanding of risk), and self-efficacy (selfperceived ability to limit disaster impacts) to be effective. However, there is limited understanding of how social capital, risk perceptions, and self-efficacy interact. We seek to explore how social capital interacts with variables known to increase the likelihood of successful adaptation. To study these linkages we analyze survey data of 1010 respondents across two communities in Thua Tien-Hue Province in central Vietnam, using ordered probit models. We find positive correlations between social capital, risk perceptions, and self-efficacy overall. This is a partly contrary finding to what was found in previous studies linking these concepts in Europe, which may be a result from the difference in risk context. The absence of an overall negative exchange between these factors has positive implications for proactive flood risk adaptation.
\end{abstract}

Keywords Flood risk - Protection motivation theory $\cdot$ Risk perceptions $\cdot$ Social capital $\cdot$ Selfefficacy $\cdot$ Vietnam

Paul Hudson

phudson@uni-potsdam.de

1 Institute of Environmental Science and Geography, University of Potsdam, 14476 Potsdam, Germany

2 Institute for Environmental Studies, Vrije University, 1081 HV Amsterdam, The Netherlands

\section{Introduction}

Flooding is the most prominent natural hazard due to its large impacts at both the social and individual level, which are predicted to continue growing globally (IPCC 2014). Moreover, it has been long recognized that disaster events are the result of human behavior interacting with nature (White 1945; Ball 1975; O'Keefe et al. 1976). O'Keefe et al. (1976) argue that an increasing trend in disasters was caused mostly by the growing vulnerability of people rather than by changes in nature. This is based on the arguments presented in White (1945) in that a range of adjustments to human behavior and action was required instead of a focus on controlling water to limit flood risk. While this has been long known, there has been in recent years a growing interest in risk governance or integrated risk management approaches in which all stakeholders that are threatened by floods play an active role (Tran et al. 2008; Hartmann and Driessen 2017).

One way stakeholders limit flood impacts is via property-level adaptation measures, which are where an individual alters aspects of their building to reduce flood damage susceptibility. A second method is through collective community-based adaptation (Reid 2016; Hagedoorn et al. 2019). An example of which is ecosystembased adaptation (EbA) strategies; these are called for as part of the Sendai Framework due to an ability to provide a range of benefits next to flood protection (Nguyen et al. 2017). Previous research has explored the factors that promote the use of these measures, and a significant number of studies has used the Protection Motivation Theory (PMT) as a theoretical foundation (Bubeck et al. 2012; Bamberg et al. 2017; van Valkengoed and Steg 2019). Protection Motivation Theory aims to capture the cognitive process of individuals when faced with risky 
outcomes. Important PMT variables are perceived risk and perceived self-efficacy. These concepts are arguably subjectively determined (Aven and Kristensen 2005), which can be impacted by how individuals are embedded in society (Schwandt 1998; Snape and Spencer 2003), and can be measured via their social capital stocks.

Social capital refers to the strength and complexity of relationships between people within and beyond their communities (Bourdieu 1986; Coleman 1988; Putnam 2001) as well as their unwritten rules (Onyx and Bullen 2000; Pretty 2003; Ostrom 2009). Social capital elements, such as trust and public participation, can build support for effective individual and community-based adaptation (Gamper and Turcanu 2009; Norris et al. 2009). Additionally, social capital not only plays a role in adaptation, but is also important for achieving collective goals via social bonds, trust, reciprocity, and shared norms (Putnam 1995; Pretty 2003; Ostrom and Ahn 2009). Relatively little is known, however, about how social capital influences PMT, overall and in particular within developing countries, even though existent studies indicate that social capital could play an important role in determining the overall relationship (Babcicky and Seebauer 2017).

Due to the importance of local conditions, there are mixed results for how social capital, PMT, and adaptation could be linked. For instance, Babcicky and Seebauer (2017) find that social capital can promote a negative exchange between risk perceptions and self-efficacy. Wolf et al. (2010) also detect ambivalent effects of social capital on vulnerability. Together these studies indicate that further testing is required regarding the generalizability of their findings within a broader range of social capital concepts across a range of research contexts. Therefore, while the preceding literature is valid it must be retested in different temporal, environmental, and cultural contexts where findings could differ (Henrich et al. 2010). In doing so, we better understand how these concepts are linked and allow for improved risk communication and dissemination activities (Slovic 1993), ultimately leading to successful risk management.

We act upon this call via the research question: what is the potential exchange between risk perceptions and selfefficacy via bonding social capital and its various subelements? We break down social capital into its subelements in order to investigate which aspects of social capital transmit any detectable exchange. Moreover, we apply PMT and social capital to Vietnam in order to better understand the potential for local initiative in finding a positive role for social capital in adaptation, rather than the negative to ambiguous role isolated in Western Europe. Overall, we believe that we contribute to the literature by increasing the range of topics studied in Vietnam, where research has focused on understanding flood damage
(Chinh et al. 2016). This is important because the existing literature has tended to focus on samples from Western, Educated, Industrialized, Rich, and Democratic (WEIRD) countries (Bubeck et al. 2012; Bamberg et al. 2017; van Valkengoed and Steg 2019). Our study explores how generalizable previous literature findings are in new contexts, such as that of Babcicky and Seebauer (2017), to refine our understanding of the complexity of the relationship between social capital and adaptive actions as presented in Wolf et al. (2010). The preceding literature in WEIRD countries may not be readily generalizable without additional research (Henrich et al. 2010) like ours.

\section{Aspects of Protection Motivation Theory and Social Capital}

This section describes the relevant aspects of Protection Motivation Theory and social capital that are employed in this study.

\subsection{Protection Motivation Theory}

Protection Motivation Theory (PMT) was developed through Rogers (1975, 1983) and Maddux and Rogers (1983). Initially its focus was on health research but currently it is also being applied to disaster research. Protection Motivation Theory captures two key cognitive processes that individuals undergo when faced with risk.

One element is threat appraisal, or risk perception (Grothmann and Reusswig 2006), which is where the individuals in question acknowledge that they are threatened by flooding. Threat appraisal also comprises perceived vulnerability (or perceived probability) and perceived severity (or perceived consequence). These concepts can be affected by various heuristics, causing threat appraisals to fall as the perceived tangibility of the event diminishes as time moves on (Tversky and Kahneman 1973; Arthurton 1998).

The second component is coping appraisal, which consists of response costs, response efficacy, and self-efficacy. Response costs are the costs associated with undertaking measures that limit the impacts of flooding; these are not limited to financial costs, but can also include time or nuisances. Response efficacy is the degree to which the possible measure is considered to be effective at limiting the impacts of flooding. Self-efficacy is the perceived ability of the individual to undertake and employ measures that limit the impacts of flooding.

Bubeck et al. (2012), Bamberg et al. (2017), and van Valkengoed and Steg (2019) review studies on PMT and flooding adaptation. They show that adaptation occurs when both risk perception and copping appraisals (in our 
case self-efficacy) are high, although they indicate that coping appraisal as a whole may have a larger influence than threat appraisal for predicting risk-reducing behavior. Most of the reviewed studies focused on developed nations, despite the successfully application of PMT in developing countries (Gebrehiwot and van der Veen 2015; Keshavarz and Karami 2016; Zheng and Dallimer 2016).

\subsection{Social Capital}

Hanifan (1916) originally defined social capital as social cohesion and personal investment in a community, later supported by Bourdieu's (1977) argument of the importance of place in peoples' lives. Based on these concepts, Pelling and High (2005) categorize social capital into three types: bonding, bridging, and linking social capital. Bonding social capital refers to relationships between individuals who share a social identity (Pelling and High 2005), for example, the connections within a family or community. Bridging social capital concerns social relationships between people with contrasting social identity, but with shared interests (Pelling and High 2005). An example is the membership of a Fisherman's Association connecting individuals through a shared fishing interest. Linking social capital crosses group boundaries in a vertical direction, such as between international donors and communities (Pelling and High 2005).

Out of these sub-types of social capital, we focus on bonding social capital, as successfully employed in the Hagedoorn et al. (2019) investigation of community-based adaption. Moreover, bonding social capital plays an important role during recovery from disaster events (Buckland and Rahman 1999; Pelling and High 2005). Bonding social capital can be developed through trust, reciprocity, social norms, and participation (Onyx and Bullen 2000; Pretty 2003; Pelling and High 2005; Ostrom 2009). Based on the preceding literature on social capital we can divide bonding social capital into the following subelements-trust, reciprocity, participation, and social norms.

Trusting other members of the community is an important underlying trigger of collective action and can be defined as the expectation of regular, honest, and cooperative behavior, thereby enhancing the willingness to take actions in a social context (Onyx and Bullen 2000; Pelling and High 2005; Ostrom 2009).

Reciprocity is when an individual who provides a service to others, or sacrifices some benefit for the sake of others, expects that this favor will be returned at some moment in the future when necessary (Onyx and Bullen 2000; Pelling and High 2005). For instance, the individual will provide a neighbor with supplies when they run out, and expects the same from the neighbor (Onyx and Bullen 2000; Ostrom 2009).

Participation within a community is described by Onyx and Bullen (2000) as an activity that is required to develop social capital, and is the basis for other social capital aspects. Namely, participation in community activities supports and reinforces elements of social capital among the members of the social group.

Social norms are generally unwritten rules that are nonetheless understood by the social group in question and guide the behavioral patterns in a given social context, providing a form of informal social control or institution (Onyx and Bullen 2000; Pretty 2003; Ostrom 2009). For instance, a community understanding regarding at which time certain communal fishing areas become available for fishing is a social norm.

\subsection{Social Capital and Potential Links with Protection Motivation Theory Aspects}

The potential link between social capital and PMT has been noted in the literature as threats that are perceived to be controllable, that is their occurrence or impacts can be limited, and thus are seen as less threatening (Slovic et al. 1984; Slovic 1987). Higher risk perceptions lead to a higher probability of undertaking action to control the threat (Kraus and Slovic 1988); these two findings overlap with research on PMT and social capital.

In line with PMT, Bubeck et al. (2012) suggest that learning from the social environment positively influences risk-reducing behavior. Działek et al. (2013) and Siegrist and Gutscher (2006) demonstrate how bonding social capital strengthens memories about past disasters while bridging social capital spreads awareness. Scolobig et al. (2012) found that higher levels of community embedding were linked with higher evaluations of community-level preparedness. Lo (2013) supports this finding by noting the positive importance of social networks and norms regarding insurance purchase in Australia, and discusses how social norms may also positively influence risk perceptions. Lo and Chan (2017) find that active social networks increased peoples' intentions to prepare for extreme weather events. Lo et al. (2015) also reveal a positive relationship between social capital and community resilience in China.

A growing literature in recent years investigates social capital and risk reduction activities, but these studies tend to focus on only one aspect of PMT rather than how social capital may interplay across multiple PMT aspects. However, Babcicky and Seebauer (2017) show that there can be opposing effects between the two elements of PMT. Wolf et al. (2010) also detect ambivalent effects of social capital and conclude that it is unclear whether social capital 
increases or reduces vulnerability. These conclusions highlight the need to disaggregate social capital into its subelements in order to detect the origin of these ambivalent effects. Furthermore, as behavioral results may not be immediately transferable, it is important to account for local conditions (Henrich et al. 2010). Therefore, we must investigate these relations across contexts in order to draw robust inferences from the wider patterns within the studied linkages.

\section{Data and Methodology}

The case study area and survey approach employed in this study are presented in Sect. 3.1, and the empirical methodology and data are presented in Sect. 3.2.

\subsection{Survey and Dataset Descriptions}

In this subsection, the case study area is presented first, followed by the survey methodology.

\subsubsection{Case Study Area}

Our study area is Thua Thien-Hue Province in central Vietnam (Fig. 1). The province houses over 1 million

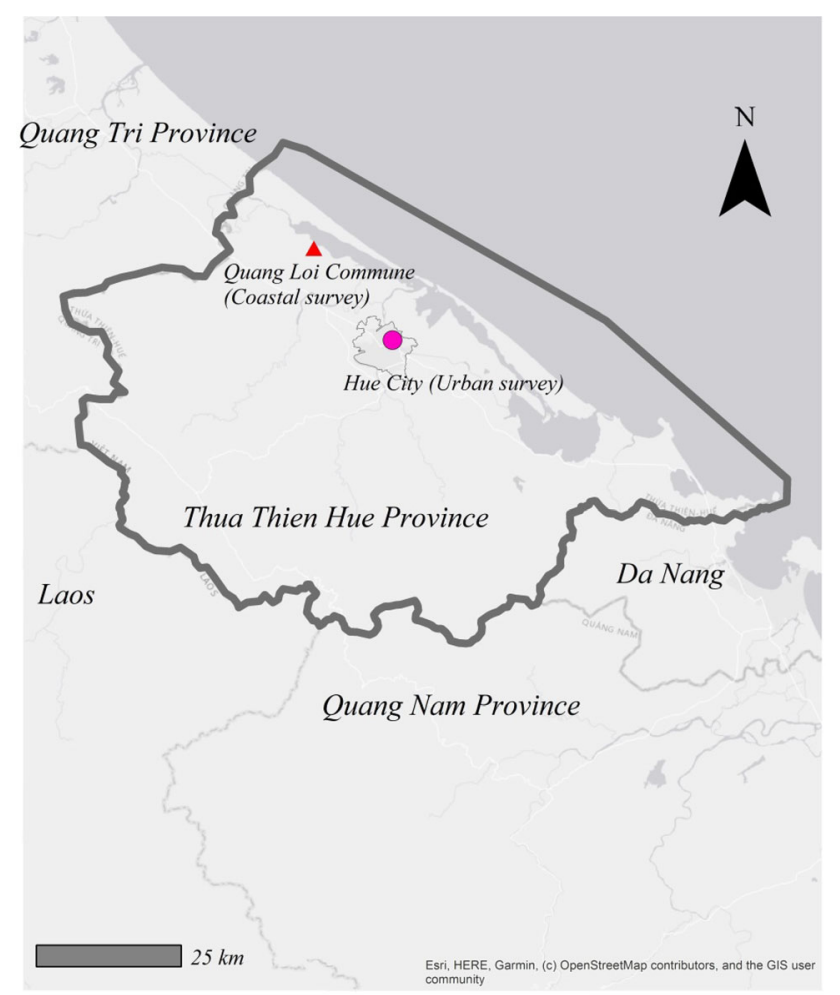

Fig. 1 Location of the survey sites within Thua Thien-Hue Province in central Vietnam residents. The Huong River and the Tam Giang Lagoon are key water features of the province and integral for the lives of up to 300,000 households (CSRD 2015). This location results in regular flooding-for example, between 1975 and 2005 there were 40 flood events with varying impacts (Bubeck et al. 2012).

The 1999 flood is the worst flood in recent Vietnamese history; it killed at least 547 people and resulted in a loss of USD 200 million across Central Vietnam (Valeriano et al. 2009). A flood in September 2009 resulted in a reported USD 19 million in damage across Thua Tien-Hue (World Bank 2010). The most recent flood was in November 2017 and led to USD 37 million in damage and the loss of nine lives across the province. Combing the flood impact simulation data from the Global Flood Risk with IMAGE Scenarios (GLOFRIS) model cascade (Ward et al. 2013; Winsemius et al. 2013) for flood return periods between $1 / 2$ to $1 / 1000$ years and the Flood Protection Standards (FLOPROS) database entry for Thua Thien Hue (Scussolini et al. 2016) generates a loss-probability curve. From this curve an annual flood risk of USD 30 million in 2010 values for the province as a whole can be inferred.

Tran et al. (2008) find that the flood coping mechanisms employed in Thua Thien-Hue are under increasing socioenvironmental pressure. Both Tran et al. (2008) and $\mathrm{Vu}$ and Ranzi (2017) conclude that integrated flood risk management is required for coping with flood events through active inclusion of community actions as a complement to actions of local flood management committees.

\subsubsection{Data Collection and Description}

Data were collected, via Kobo Toolbox, through face-toface interviews during June and September 2017 by a team of 14 local enumerators. In total 1010 residents were interviewed, equally divided over a rural and an urban community generating a sample that is representative of the province. For a detailed discussion of the sampling approach please see Hudson et al. (2019b).

The questionnaire covered seven issues: dependence on ecosystem services and environmental perceptions; wellbeing; risk perceptions; a discrete choice experiment; social capital; flood experiences; and demographics. The questionnaire was used to support the design of community-based adaptation and flood risk management strategies in the study area (DKKV 2019). The questionnaire was developed across international and local researchers and a local nongovernmental organization, while being embedded in the scientific literature (Onyx and Bullen 2000; Poussin et al. 2013; Botzen et al. 2015; Bubeck and Thieken 2018; Hagedoorn et al. 2019). The survey was adapted following three pretest surveys $(N \approx 210)$. For 
instance, all Likert scales were harmonized to 11 point scales based on participant feedback.

The dependent variables are those for risk perceptions and self-efficacy (Table 1). The respondents answered four questions related to their flood risk perceptions that were combined as one variable to increase the comparability to Babcicky and Seebauer (2017). The wording we employ for self-efficacy was similar to the one used in Babcicky and Seebauer (2017): "It is too difficult for someone like me to protect against flooding." We do not address response cost and response efficacy, the other components of coping appraisal.

The overall bonding social capital variable is a composition of nine survey questions related to the different studied social capital elements. The study of Onyx and Bullen (2000) draws upon previous work [for example, Coleman (1988), Putnam (1995), see Onyx and Bullen (2000) for more detailed references], and empirically tested 68 potential social capital items. Hagedoorn et al. (2019) successfully employed a similar set of questions in Micronesia. Additionally, the selected subelements of bonding social capital are also included to look into their influence. Bridging social capital is measured by asking the survey respondents to state the number of formal and informal social networks in which they take part, without considering their potential quality.

\subsection{Data Analysis}

The epistemological assumptions for understanding our results and approach are constructivist, supposing that knowledge is the product of social development and interaction (Schwandt 1998; Snape and Spencer 2003). We argue that social interactions determine a respondents' knowledge of reality, their risk perceptions, degree of social interconnections, and self-efficacy. Hence, risk can be considered as a judgment rather than a fact that depends on the information and understanding of the individual (Aven and Kristensen 2005). Therefore, interviewee answers reflect their subjective understanding of the world and what they can do, which may not match objective reality. For example, see the availability heuristics known to affect behavior (Tversky and Kahneman 1973), the role of human cognition regarding adaptive behavior (Grothmann and Patt 2005; Grothmann and Reusswig 2006), or how judgments on risk and probability differ between experts and lay people (Fischhoff et al. 1978; Renn 1998; Slovic 1998; Weber and Hsee 1998). This is also in line with ontological idealism, which maintains that reality can only be understood via the human mind and socially constructed meanings (Snape and Spencer 2003). This approach is suitable because Bourdieu (1977) connects social capital to the location in which people live, meaning that empirical relationships can be expected to differ across different regions (Mohan and Mohan 2002).

In conducting the statistical analysis, an ordered probit regression of the social capital and control variables on risk perceptions and self-efficacy are used. This is because the dependent variables are ordinal with a natural ordering of values.

\section{Results and Discussion}

This section comprises the results, possible limitations, and implications for policy and research.

\subsection{Results}

The results are presented in Table 2: M1 presents the model results, including the combined bonding social capital variable; and M2 displays results for the model including the subelement variables. Regression coefficients are presented rather than marginal effects, to avoid presenting 11 sets of marginal effects. However, while the magnitude of the estimate would differ the overall conclusion does not.

Concerning the control variables, a consistent result is that the correlation between the dependent variables and age is rather weak. This is because the only significant relationship, concerning age, was found with risk perceptions. The same holds for the income, married, and household size variables. The impact of having experienced more severe flood events tends to be associated with dependent variables in a way that one could expect. Namely, it is known that people's awareness of flooding can increase in line with the severity of the event experienced (Windham et al. 1977; Perry and Lindell 1990; Norris et al. 1999; Riad et al. 1999). The relationship with self-efficacy is because people with severe experiences could feel more helpless (Soane et al. 2010) due to traumatic experiences and the feeling that flooding is less controllable. This is especially true if employed protective measures fail during an event (Weinstein 1989). Failing to consider these issues and their interaction can explain inconsistencies regarding experience-behavior outcomes (Weinstein 1989). The estimated correlation regarding education and coastal is negative for risk perceptions but positive for self-efficacy. This can be interpreted as education providing a higher sense of capability to employ various adaptive behaviors, which reduces the perceived threat posed by flooding as the respondent feels more capable of managing flood impacts (Slovic et al. 1984; Slovic 1987). The same can be argued for coastal as compared to the results from Hue City (the urban survey area), the coastal communities are less likely to benefit 
Table 1 Description of key variables in social capital, flood risk perception, and self-efficacy study

\begin{tabular}{ll}
\hline Variable name & Definition \\
\hline $\begin{array}{l}\text { Dependent variables } \\
\text { Risk perceptions }\end{array}$ & $\begin{array}{l}\text { The average value across: } \\
\text { In your opinion: in an average year, will you be affected by a flood? }(0=\text { impossible, } 10=\text { for sure })\end{array}$ \\
& $\begin{array}{l}\text { If you are affected, how bad will the impact be? }(0=\text { no impact, } 10=\text { extreme impact }) \\
\text { Do you generally worry about the impacts of flooding? }(0=\text { not at all, } 10=\text { very much }) \\
\text { How do you think the threat of flooding will change in the future? }(0=\text { decrease a lot, } 10=\text { increase a } \\
\text { lot })\end{array}$
\end{tabular}

Self-efficacy

Independent variables

Participation

Trust

Reciprocity

Social norms

Bonding

Bridging

Female

Age

Coastal

Severity of previous flood events

Income
The respondent's self-stated response to:

Summary

Statistics

Nothing can prevent "flood" from occurring or reducing the damage it causes? $(0=$ completely agree, $10=$ completely disagree)

$M=6.81$

$\mathrm{SD}=1.65$

$N=940$

The average value across $(0=$ completely disagree, $10=$ completely agree $)$ :

Members of my household often participate in community activities

I regularly interact with other members of my community, also if there are no activities planned

My household is actively involved in a local management committee

The respondent's self-stated response to $(0=$ completely disagree, $10=$ completely agree $)$ :

Most people in my community can be trusted

$M=3.86$

$\mathrm{SD}=2.45$

$N=987$

$M=5.31$

$\mathrm{SD}=1.8$

$N=1005$

$M=6.72$

$\mathrm{SD}=1.52$

$N=1004$

$M=6.99$

$\mathrm{SD}=1.36$

I am confident that in a time of need a member of the community will help me

$N=1004$

By helping others you help yourself

The average value across $(0=$ completely disagree, $10=$ completely agree $)$ :

$M=7.37$

My community is very united

$\mathrm{SD}=1.35$

I feel very accepted and at home in my community

The average value across the respondent's responses regarding the individual questions for Participation, Trust, Reciprocity, and Social Norms.

$N=1006$

$M=6.5$

$\mathrm{SD}=1.14$

$N=1001$

The respondent's self-stated number of important social networks they are involved with (e.g. elderly association, choral groups)

$M=0.6$

$\mathrm{SD}=0.58$

$N=1010$

$M=0.45$

$\mathrm{SD}=0.5$

$N=1010$

$M=48$

$\mathrm{SD}=13$

$N=1006$

A dummy variable taking the value of 1 if the respondent is located in the rural/coastal study area and 0 otherwise

$M=0.5$

$\mathrm{SD}=0.5$

$N=1010$

$M=6.67$

$\mathrm{SD}=1.76$

$N=1006$

Overall, how severe have the impacts of your own flood experience(s) been?

$M=8.08$

$\mathrm{SD}=5.99$

$N=1005$ 
Table 1 continued

\begin{tabular}{|c|c|c|}
\hline Variable name & Definition & $\begin{array}{l}\text { Summary } \\
\text { Statistics }\end{array}$ \\
\hline Finished high school & $\begin{array}{l}\text { A dummy variable taking the value of } 1 \text { if the respondent stated that their highest level of completed } \\
\text { education was high school and } 0 \text { otherwise }\end{array}$ & $\begin{array}{l}M=0.43 \\
\mathrm{SD}=0.5 \\
N=1006\end{array}$ \\
\hline Finished university & $\begin{array}{l}\text { A dummy variable taking the value of } 1 \text { if the respondent stated that their highest level of completed } \\
\text { education was at university level or higher, and } 0 \text { otherwise }\end{array}$ & $\begin{array}{l}M=0.16 \\
\mathrm{SD}=0.37 \\
N=1006\end{array}$ \\
\hline Married & $\begin{array}{l}\text { A dummy variable taking the value of } 1 \text { if the respondent stated that they were married, and } 0 \\
\text { otherwise }\end{array}$ & $\begin{array}{l}M=0.91 \\
\mathrm{SD}=0.29 \\
N=1006\end{array}$ \\
\hline Household size & The respondent's self-stated number of members of their current household & $\begin{array}{l}\mathrm{M}=4.45 \\
\mathrm{SD}=1.66 \\
N=1001\end{array}$ \\
\hline
\end{tabular}

$M$ mean, $S D$ standard deviation, $N$ number of responses

from governmental recovery support (DKKV 2019), which creates an incentive for coastal respondents to develop this self-capacity.

Turning to social capital, the results in Table 2 show an overall positive link between social capital and both risk perceptions and self-efficacy as bonding social capital has a statistically significant (at the $1 \%$ level) positive correlation for both dependent variables. On the other hand, bridging social capital has a negative correlation overall, but is hardly statistically significant. This may be because the quality of these networks is unknown, limiting its usefulness. Therefore, in aggregate tighter social ties are associated with higher threat appraisal and self-efficacy.

In order to better understand the relation between social capital and the dependent variables, we break bonding social capital into four subelements (M2 in Table 2) to more deeply understand our initial findings. The results for three of the subelements - trust, reciprocity, and social norms-indicate the potential source for a positive association between risk perceptions and self-efficacy. Namely, trust and reciprocity are reinforced by social norms so that respondents believe that they can reliably expect and benefit from the help of others within their community while undertaking adaptive behavior, rendering adaptation more likely to be successful. These tighter social connections, in turn, increase the perceived subjective impacts of flooding. For instance, Hudson et al. (2019a) find a negative well-being effect on those who had neighbors flooded but they themselves were not impacted, showing that tighter social connections can reinforce this subjective impact through vicarious experiences (Terpstra et al. 2009).

The results for the participation subelement of bonding social capital indicate a possible exchange between risk perceptions and self-efficacy, since we see a negative association with self-efficacy, but a positive association with risk perceptions. The positive association with risk perceptions is due to the previous described effect of higher subjective impacts from floods due to tighter social connections and that in Vietnam negative flood impacts are common. This increases the tangibility of the threat and so raises the threat appraisal. This supports the finding in Działek et al. (2013), where social capital was found to strengthen the memory of flood events. However, this in turn could emphasize the need for collective action resulting in a decrease of individual capacity, similar to the process argued in Soane et al. (2010) for traumatic events. This could also be seen from the positive association between self-efficacy and social norms, which could be interpreted to show that stronger unwritten rules for direct or indirect support for positive behavior can overcome aspects of the loss of individual autonomy. The relative sizes of the coefficients could indicate that the positive association of social norms may outweigh the negative association of participation on self-efficacy. This further reinforces, and extends, the finding of Lo (2013) in Australia, who observes that social norms are important for insurance purchase.

A further observation regards the change in coefficient sizes as the social capital concept is disaggregated in moving from M1 to M2. Concerning self-efficacy (M1), we 
Table 2 Estimated regression coefficients between risk perceptions, self-efficacy, and social capital

\begin{tabular}{|c|c|c|c|c|}
\hline \multirow{2}{*}{$\begin{array}{l}\text { Dependent variable } \\
\text { Final model type }\end{array}$} & \multicolumn{2}{|c|}{ Combined risk perception } & \multicolumn{2}{|c|}{ Self-efficacy } \\
\hline & M1 & M2 & M1 & M2 \\
\hline Female & $\begin{array}{l}-0.02 \\
(0.08)\end{array}$ & $\begin{array}{l}-0.02 \\
(0.08)\end{array}$ & $\begin{array}{l}-0.11 \\
(0.07)\end{array}$ & $\begin{array}{l}-0.13^{*} \\
(0.07)\end{array}$ \\
\hline Age & $\begin{array}{l}-0.007 * * * \\
(0.003)\end{array}$ & $\begin{array}{l}-0.007^{* * *} \\
(0.003)\end{array}$ & $\begin{array}{l}0.001 \\
(0.003)\end{array}$ & $\begin{array}{l}0.001 \\
(0.003)\end{array}$ \\
\hline Coastal & $\begin{array}{l}-0.18^{* *} \\
(0.09)\end{array}$ & $\begin{array}{l}-0.19 * * \\
(0.09)\end{array}$ & $\begin{array}{l}0.30 * * * \\
(0.09)\end{array}$ & $\begin{array}{l}0.32 * * * \\
(0.09)\end{array}$ \\
\hline Severity of previous flood events & $\begin{array}{l}0.22 * * * \\
(0.02)\end{array}$ & $\begin{array}{l}0.22 * * * \\
(0.02)\end{array}$ & $\begin{array}{l}-0.22 * * * \\
(0.02)\end{array}$ & $\begin{array}{l}-0.24 * * * \\
(0.02)\end{array}$ \\
\hline Income & $\begin{array}{l}-0.01 * * \\
(0.007)\end{array}$ & $\begin{array}{l}-0.01 * * \\
(0.007)\end{array}$ & $\begin{array}{l}-0.004 \\
(0.006)\end{array}$ & $\begin{array}{l}0.0009 \\
(0.006)\end{array}$ \\
\hline Finished high school & $\begin{array}{l}-0.37 * * * \\
(0.09)\end{array}$ & $\begin{array}{l}-0.37 * * * \\
(0.09)\end{array}$ & $\begin{array}{l}0.19 * * \\
(0.08)\end{array}$ & $\begin{array}{l}0.24 * * * \\
(0.08)\end{array}$ \\
\hline Finished university & $\begin{array}{l}-0.49^{* * *} \\
(0.12)\end{array}$ & $\begin{array}{l}-0.48^{* * * *} \\
(0.13)\end{array}$ & $\begin{array}{l}0.41 * * * \\
(0.12)\end{array}$ & $\begin{array}{l}0.48 * * * \\
(0.12)\end{array}$ \\
\hline Married & $\begin{array}{l}-0.071 \\
(0.12)\end{array}$ & $\begin{array}{l}-0.07 \\
(0.12)\end{array}$ & $\begin{array}{l}-0.03 \\
(0.12)\end{array}$ & $\begin{array}{l}-0.004 \\
(0.12)\end{array}$ \\
\hline Household size & $\begin{array}{l}0.034 \\
(0.022)\end{array}$ & 0.04 & $\begin{array}{l}0.043 * * \\
(0.02)\end{array}$ & $0.04 *$ \\
\hline Bonding social capital & $\begin{array}{l}0.22 * * * \\
(0.03)\end{array}$ & $(0.02)$ & $\begin{array}{l}0.07 * * \\
(0.03)\end{array}$ & $(0.02)$ \\
\hline Participation & & $\begin{array}{l}0.07 * * * \\
(0.02)\end{array}$ & & $\begin{array}{l}-0.05^{* * * *} \\
(0.02)\end{array}$ \\
\hline Trust & & $\begin{array}{l}0.07 * * \\
(0.03)\end{array}$ & & $\begin{array}{l}0.008 \\
(0.03)\end{array}$ \\
\hline Reciprocity & & $\begin{array}{l}0.08 * * \\
(0.04)\end{array}$ & & $\begin{array}{l}0.005 \\
(0.04)\end{array}$ \\
\hline Social norms & & $\begin{array}{l}-0.005 \\
(0.04)\end{array}$ & & $\begin{array}{l}0.14 * * * \\
(0.04)\end{array}$ \\
\hline Bridging & $\begin{array}{l}-0.1 \\
(0.07)\end{array}$ & $\begin{array}{l}-0.11 \\
(0.07)\end{array}$ & $\begin{array}{l}-0.04 \\
(0.07)\end{array}$ & $\begin{array}{l}-0.02 \\
(0.07)\end{array}$ \\
\hline Observations & 940 & & 978 & \\
\hline
\end{tabular}

Values outside (within) of parenthesis are parameter (standard error) estimates; $* * * p<0.01, * * p<0.05, * p<0.1$

see that in moving from $\mathrm{M} 1$ to $\mathrm{M} 2$, that the coefficient of M1 is the result of the two significant subelements of bonding social capital counteracting each other to a degree. This is not true for risk perceptions, however, as the overall coefficient (M1) is much larger than the corresponding subelements (M2), despite level to little change in the other estimated coefficients or $R^{2}$. Therefore, the combined effect of the social capital subelements creates an effect larger than the sum of its parts. This is because, as compared to self-efficacy, the subelements act in the same direction, which creates a reinforcing synergy between the subelements. This reinforcement occurs because tighter social bonds strengthen peoples' understandings and recollection of the events (Działek et al. 2013; Hudson et al. 2019a). Hence, the different social capital subelements represent different avenues in which these experiences are reinforced across different thought and social processes. This is not the case for self-efficacy because of the opposite relationship between participation and social norms. This reversal takes place because the participation subelement generates tighter social bonds, reinforcing the severity of the event and creating a stronger sense that the event is uncontrollable. Hence taking action to limit impacts could be seen as pointless, the reverse of Slovic's conclusion (1987). On the other hand, the social norms element implies a social contact that people should be willing and able to help limit disaster impacts when required. Therefore, there is not a natural synergy and reinforcing effect 
between the social capital subelements and self-efficacy. We see again how one of the core findings from Weinstein (1989) regarding the impact experience on preparation can be extended based of our findings regarding social capital and PMT. This is the result of how social capital works through many aspects of the PMT rather than a single aspect. These multiple directions of impact should be accounted for across research contexts, further emphasizing the complexity of the linkages between social capital and adaptation (Wolf et al. 2010), especially in future riskmodeling.

Finally, the main source of comparison is Babcicky and Seebauer (2017). We find the opposite overall relationship to that in Babcicky and Seebauer (2017). We find a potential positive exchange, with a minor exchange between social capital subelements, but one that overall boosts social capital and could increase both threat appraisal and self-efficacy. However, this finding does initially seem to oppose a strand of previous research that has argued that a risk perceived to be controllable is seen as less threatening (Slovic et al. 1984; Slovic 1987). On the other hand, social capital plays an important role in determining both the subjective magnitude and perceptions of flooding and protective actions due to how a person's social embedding alters how an individual receives and understands vicarious flood experiences via social connections. Therefore, it is unclear a priori which direction should be systematically more powerful without taking into account the local context, as behavior in one area may not apply in another (Henrich et al. 2010), hence, the need to investigate previous studies in new contexts.

For instance, participation nearly cancels out, in raw magnitude, across self-efficacy and risk perceptions. This determination accords with previous studies in that a greater threat appraisal appears to be seen as less controllable. We see that in Vietnam, however, with a stronger collectivist approach and culture, that reciprocity and the social norm elements of bonding social capital become more important, as compared to Austria in Babcicky and Seebauer (2017). In essence the treat is recognized through closer ties that the respondents expected to be called upon in times of need and that this anticipation creates the social expectation to take part as well as the belief that when called upon they will receive the support needed to act, increasing perceived self-efficiency. The more collectivist nature of actions in Vietnam creates a feedback loop between elements of social capital that prevent the negative exchange found in Babcicky and Seebauer (2017). Therefore, while social capital links risk perceptions and selfefficacy, participation forms the basis of the limited negative exchange. The main transition mechanism of this exchange through participation is how vicarious experiences are generated and the psychological linkage of risk perceptions and self-efficacy is created. The potential differences between how participation social capital is formed and understood across Vietnam and Austria can explain why these findings differ. This difference highlights that what we learn from a literature built upon WEIRD countries needs to be explored in non-WEIRD countries (Henrich et al. 2010).

\subsection{Limitations}

A potential limitation of the article concerns the internal reliability of the items used to construct the overall concepts, which is that the items sufficiently map onto the same concept. An indication of this is Cronbach's alpha. The items used to construct risk perceptions cannot be tested as the questions are not on identical measurement scales. The Cronbach's alpha for bonding social capital is 0.75. Fields (2009) states this is suitable, since results of 0.7 (or larger) are used as an, arbitrary, indicator for suitable reliability. The value for participation is 0.57 , reciprocity is 0.81 , and social norms is 0.6 . Therefore, the more aggregated level of analysis has a higher level of reliability, potentially limiting aspects of the disaggregated analysis. This could also indicate an area of future research into adapting these concepts to Vietnam. Additionally, Kline (1999) states that for psychological constructs values below 7 can be expected due to the diversity of measured constructs.

A second potentially perceived limitation is that the explanation of the results could be seen as descriptive due to the inability of the study to detect casual relationships while remaining comparable to previous studies, that is, the nonexperimental techniques used. However, this is an area of future research in identifying and confirming the causal mechanisms of the relations presented and why they occur. For example, how trust and reciprocity are potentially reinforced by social norms or confirm the role of vicarious experiences in the exchange through participation.

\subsection{Implications}

In this subsection, the implications for local policymakers are presented first, followed by the possible implications for researchers.

\subsubsection{Policy Implications}

Flood adaptation is of growing importance to Vietnam (Tran et al. 2008). Our findings indicate that in Vietnam including social capital as part of integrated flood risk management may have positive effects on adaptive behavior. The social capital subelement results provide useful input on how to best utilize social capital. Stronger 
community ties can act as a complement to an individual's experience and thereby boost risk perceptions (Siegrist and Gutscher 2006), and the development of social norms can boost self-efficacy. Combined these lessons can lead to improved risk communication (Slovic 1993). However, a caveat is that bonding social capital may not be strong enough to form community-based strategies without a wider enabling environment.

A practical implication regards the role of ecosystembased adaptation (EbA) and the increasing need for inclusive community-based adaption due to a changing risk context (Tran et al. 2008; CSRD 2015). These issues can be addressed by an EbA that employs and restores local ecosystems to increase local community resilience (Reid 2016). This implies that EbA projects could build social capital in addition to increasing the community's flood resilience. Moreover, there are calls for participatory and bottom-up based approaches to complement more formal risk management (Tran et al. 2008).

\subsubsection{Research Implications}

Further research into how social relationships could be altered or mediated by other relationships is important, because different communities may experience different problems (Cutter 2017). A better understanding of these differences would allow for policy interventions to be better targeted and designed in order to produce the largest boost to resilience (Slovic 1993). Moreover, communitybased adaptation provides an activity for local stakeholder interaction as a base for integrated flood risk management. But a greater focus on longitudinal data collection will be necessary to evaluate whether this activity is able to causally achieve this self-reinforcing effect.

Another implication comes from the finding that subjective flood impacts are associated positively with risk perceptions, but negatively with self-efficacy. This is important because of the increasing role of behavior in risk assessment. It is often argued that experiencing a hazard increases the probability of undertaking risk reduction measures (Kraus and Slovic 1988; Weinstein 1989; Aerts et al. 2018), yet this neglects the severity of the experienced flood event, which can counteract different aspects of PMT. Therefore, focus must be placed on the possible turning point in adaption potential as otherwise inconsistencies may be developed (Weinstein 1989).

\section{Conclusions}

Flood events have large negative impacts on society, leading to the concept of integrated risk management that has been growing in importance, and requires the active involvement of local community actors to be sustainable. In that perspective, social capital is important to consider due to its role in flood resilience. For that reason, we investigated the linkages between social capital and PMT aspects (risk perceptions and self-efficacy) in a flood-prone developing country (Vietnam). This research further explores how generalizable the findings of the previous literature are to a new and broader range of contexts.

We find an overall positive relationship between social capital, risk perceptions, and self-efficacy, which provides promising opportunities for adaptation to flooding in central Vietnam. Focusing adaptation projects on increasing or preserving existing bonding social capital within a community can increase flood resilience and promote additional adaption to flooding. However, while there is a positive relationship overall there is a limited exchange between risk perceptions and self-efficacy for the participation subelement of bonding social capital.

Acknowledgements The authors acknowledge funding received from the Global Resilience Partnership (GRP) through the Water Window's ResilNam Coastal and ResilNam Urban projects as funded by the Z Zurich Foundation. The funder had no direct input on the research conducted or the ability to publish the paper.

Open Access This article is licensed under a Creative Commons Attribution 4.0 International License, which permits use, sharing, adaptation, distribution and reproduction in any medium or format, as long as you give appropriate credit to the original author(s) and the source, provide a link to the Creative Commons licence, and indicate if changes were made. The images or other third party material in this article are included in the article's Creative Commons licence, unless indicated otherwise in a credit line to the material. If material is not included in the article's Creative Commons licence and your intended use is not permitted by statutory regulation or exceeds the permitted use, you will need to obtain permission directly from the copyright holder. To view a copy of this licence, visit http://creativecommons. org/licenses/by/4.0/.

\section{References}

Aerts, J.C.J.H., W.J.W. Botzen, K.C. Clarke, S.L. Cutter, J.W. Hall, B. Merz, E. Michel-Kerjan, J. Mysiak, et al. 2018. Integrating human behaviour dynamics into flood disaster risk assessment. Nature Climate Change 8: 193-199.

Arthurton, R.S. 1998. Marine-related physical natural hazards affecting coastal megacities of the Asia-Pacific region-Awareness and mitigation. Ocean \& Coastal Management 40(1): 65-85.

Aven, T., and V. Kristensen. 2005. Perspectives on risk: Review and discussion of the basis for establishing a unified and holistic approach. Reliability Engineering \& System Safety 90(1): 1-14.

Babcicky, P., and S. Seebauer. 2017. The two faces of social capital in private flood mitigation: Opposing effects on risk perception, self-efficacy, and coping capacity. Journal of Risk Research 20(8): 1017-1037.

Ball, N. 1975. The myth of the natural disaster. The Ecologist 5(10): 368-369. 
Bamberg, S., T. Masson, K. Brewitt, and N. Nemetschek. 2017. Threat, coping and flood prevention-A meta-analysis. Journal of Environmental Psychology 54: 116-126.

Botzen, W.J.W., H. Kunreuther, and E. Michel-Kerjan. 2015. Divergence between individual perceptions and objective indicators of tail risks: Evidence from floodplain residents in New York City. Judgment and Decision Making 10(4): 365-385.

Bourdieu, P. 1977. Outline of a theory of practice. Cambridge, UK: Cambridge University Press.

Bourdieu, P. 1986. The forms of capital. In Handbook of theory and research for the sociology of education, ed. J.G. Richardson, 241-258. New York: Greenwood Press.

Bubeck, P., W.J.W. Botzen, L.T.T. Suu, and J.C.J.H Aerts. 2012. Do flood risk perceptions provide useful insights for flood risk management? Findings from central Vietnam. Journal of Flood Risk Management 5(4): 295-302.

Bubeck, P., and A.H. Thieken. 2018. What helps people recover from floods? Insights from a survey among flood-affected residents in Germany. Regional Environmental Change 18(1): 287-296.

Buckland, J., and M. Rahman. 1999. Community-based disaster management during the 1997 Red River flood in Canada. Disasters 23(2):174-191.

Chinh, D.T., P. Bubeck, N.V. Dung, and H. Kreibich. 2016. The 2011 flood event in the Mekong Delta: Preparedness, response, damage and recovery of private households and small businesses. Disasters 40(4): 753-778.

Coleman, J.S. 1988. Social capital in the creation of human capital. American Journal of Sociology 94: 95-120.

CSRD (Centre for Social Research and Development). 2015. Gender needs and roles in building climate resilience in the city of Hue, Vietnam. Asian cities climate resilience working paper series 33. London, UK: International Institute for Environment and Development.

Cutter, S.L. 2017. The forgotten casualties redux: Women, children, and disaster risk. Global Environmental Change 42:117-121.

DKKV (German Committee for Disaster Reduction). 2019. Strong roots, strong women: Women and ecosystem-based adaptation to flood risk in Central Vietnam. Bonn: German Committee for Disaster Reduction.

Działek, J., W. Biernacki, and A. Bokwa. 2013. Challenges to social capacity building in flood-affected areas of southern Poland. Natural Hazards and Earth System Sciences 13(10): 2555-2566.

Fields, A. 2009. Discovering Statistics using SPSS, 3rd edn. London: SAGE.

Fischhoff, B. P. Slovic, S. Lichtenstein, S. Read, and B. Combs. 1978. How safe is safe enough? A psychometric study of attitudes towards technological risks and benefits. Policy Sciences 9(2): $127-152$.

Gamper, C.D., and C. Turcanu. 2009. Can public participation help managing risks from natural hazards. Safety Science 47(4): 522-528.

Gebrehiwot, T., and A. van der Veen. 2015. Farmers prone to drought risk: Why some farmers undertake farm-level risk-reduction measures while others not? Environmental Management 55(3): 588-602.

Grothmann, T., and A. Patt. 2005. Adaptive capacity and human cognition: The process of individual adaptation to climate change. Global Environmental Change 15(3): 199-213.

Grothmann, T., and F. Reusswig. 2006. People at risk of flooding: Why some residents take precautionary action while others do not. Natural Hazards 38(1-2): 101-120.

Hagedoorn, L.C., L.M. Brander, P.J.H. van Beukering, H.M. Dijkstra, C. Franco, L. Hughes, I. Gilders, and B. Segal. 2019. Community-based adaptation to climate change in small island developing states: An analysis of the role of social capital. Climate and Development 11(8): 723-734.
Hanifan, L.J. 1916. The rural school community center. Annals of the American Academy of Political and Social Science 67(1). https:// doi.org/10.1177/000271621606700118.

Hartmann, T., and P. Driessen. 2017. The flood risk management plan: Towards spatial water governance. Journal of Flood Risk Management 10(2): 145-154.

Henrich, J., S.J. Heine, and A. Norenzayan. 2010. The weirdest people in the world? Behavioral and Brain Sciences 33(2-3): 61-83.

Hudson, P., W.J.W. Botzen, J.K. Poussin, and J.C.J.H. Aerts. 2019. The impacts of flooding and flood preparedness on happiness: A monetisation of the tangible and intangible subjective well-being impacts. Journal of Happiness Studies 20(2): 665-682.

Hudson, P., M. Pham, and P. Bubeck. 2019. An evaluation and monetary assessment of the impact of flooding on subjective well-being across genders in Vietnam. Climate and Development 11(7): 632-637.

IPCC (Intergovernmental Panel on Climate Change). 2014. Climate change 2014: Synthesis report. Contribution of working groups I, II and III to the fifth assessment report of the Intergovernmental Panel on Climate Change, ed. R. Pachauri, and L. Meyer. Geneva, Switzerland: IPCC.

Keshavarz, M., and E. Karami. 2016. Farmers' pro-environmental behavior under drought: Application of protection motivation theory. Journal of Arid Environments 127: 128-136.

Kline, P. 1999. A handbook of psycological testing, 2nd edn. London: Routledge.

Kraus, N.N., and P. Slovic. 1988. Taxonomic analysis of perceived risk: Modeling individual and group perceptions within homogeneous hazard domains. Risk Analysis 8(3): 435-455.

Lo, A.Y. 2013. The role of social norms in climate adaptation: Mediating risk perception and flood insurance purchase. Global Environmental Change 23(5): 1249-1257.

Lo, A.Y., and F. Chan. 2017. Preparing for flooding in England and Wales: The role of risk perception and the social context in driving individual action. Natural Hazards 88(1): 367-387.

Lo, A.Y., B. Xu, F.K.S. Chan, and R. Su. 2015. Social capital and community preparation for urban flooding in China. Applied Geography 64: 1-11.

Maddux, J.E., and R.W. Rogers. 1983. Protection motivation and selfefficacy: A revised theory of fear appeals and attitude change. Journal of Experimental Social Psychology 19(5): 469-479.

Mohan, G., and J. Mohan. 2002. Placing social capital. Progress in Human Geography 26(2): 191-210.

Nguyen, T.T., J. Pittock, and B.H. Nguyen. 2017. Integration of ecosystem-based adaptation to climate change policies in Viet Nam. Climatic Change 142(1): 97-111.

Norris, F.H., T. Smith, and K. Kaniasty. 1999. Revisiting the experience-behavior hypothesis: The effects of hurricane Hugo on hazard preparedness and other self-protective acts. Basic and Applied Social Psychology 21(1): 37-47.

Norris, F.H., S.P. Stevens, B. Pfefferbaum, K.F. Wyche, and R.L. Pfefferbaum. 2009. Community resilience as a metaphore, theory, set of capacities, and strategy for disaster prepardness. American Journal of Community Psychology 41(1-2): 127-150.

O'Keefe, P., K. Westgate, and B. Wisner. 1976. Taking the naturalness out of natural disasters. Nature 260(5552): 566-567.

Onyx, J., and P. Bullen. 2000. Measuring social capital in five communities. The Journal of Applied Behavioural Science 36(1): $23-42$.

Ostrom, E. 2009. A general framework for analyzing sustainability of social-ecological systems. Science 325(5939): 419-422.

Ostrom, E., and T. Ahn. 2009. The meaning of social capital and its link to collective action. In Handbook of social capital: The troika of sociology, political science and economics, ed. G.T. 
Svendsen, and G.L.H. Svendsen, 17-35. Cheltenham: Edward Elgar.

Pelling, M., and C. High. 2005. Understanding adaptation: What can social capital offer assessments of adaptive capacity. Global Environmental Change 15(4): 308-319.

Perry, R.W., and M.K. Lindell. 1990. Predicting long-term adjustment to Volcano hazard. International Journal of Mass Emergencies and Disasters 8(2): 117-136.

Poussin, J.K., W.J.W. Botzen, and J.C.J.H. Aerts. 2013. Stimulating flood damage mitigation through insurance: An assessment of the French CatNat system. Environmental Hazards 12(3-4): 258-277.

Pretty, J. 2003. Social capital and the collective management of resources. Science 302(5652): 1912-1914.

Putnam, R.D. 1995. Bowling alone: America's declining social capital. Journal of Democracy 6(1): 65-78.

Putnam, R.D. 2001. Social capital: Measurement and consequences. Isuma: Canadian Journal of Policy Research 2(1): 41-51.

Reid, H. 2016. Ecosystem- and community-based adaptation: Learning from community-based natural resource management. Climate and Development 8(1): 4-9.

Renn, O. 1998. The role of risk perception for risk management. Reliability Engineering \& System Safety 59(1): 49-62.

Riad, J.K., F.H. Norris, and R.B. Ruback. 1999. Predicting evacuation in two major disasters: Risk perception, social influence, and access to resources. Journal of Applied Social Psychology 29(5): 918-934.

Rogers, R.W. 1975. A protection motivation theory of fear appeals and attitude change. The Journal of Psychology 91(1): 93-114.

Rogers, R.W. 1983. Cognitive and physiological processes in fear appeals and attitude change: A revised theory of protection motivation. In Social Psychophysiology: A Sourcebook, ed. J.T. Cacioppo, and R.E. Petty, 157-176. New York: Guilford Press.

Schwandt, T.A. 1998. Constructivist, interpretivist approaches to human inquiry. In The landscape of qualitative research, ed. N.K. Denzin, and Y.S. Lincon, 118-137. Thousand Oaks, CA: Sage Publications.

Scolobig, A., B. De Marchi, and M. Borga. 2012. The missing link between flood risk awareness and preparedness: Findings from case studies in an Alpine Region. Natural Hazards 63(2): 499-520.

Scussolini, P., J.C.J.H. Aerts, B. Jongman, L. Bouwer, H.C. Winsemius, H. de Moel, and P.J. Ward. 2016. FLOPROS: An evolving global database of flood protection standards. Natural Hazards and Earth System Sciences 16: 1049-1061.

Siegrist, M., and H. Gutscher. 2006. Flooding risks: A comparison of lay people's perceptions and expert's assessments in Switzerland. Risk Analysis 26(4): 971-979.

Slovic, P. 1987. Perception of risk. Science 236(4799): 280-285.

Slovic, P. 1993. Perceived risk, trust, and democracy. Risk Analysis 13(6): 675-682.

Slovic, P. 1998. The risk game. Reliability Engineering \& System Safety 59(1): 73-77.

Slovic, P., B. Fischhoff, and S. Lichtenstein. 1984. Behavioral decision theory perspectives on risk and safety. Acta Psychologica 56(1): 183-203.

Snape, D., and L. Spencer. 2003. The foundations of qualitative research: A guide for social science students and researchers. In Qualitative research practice, ed. J. Ritchie, and J. Lewis, 1-23. Thousand Oaks, CA: Sage Publications.
Soane, E., I. Schubert, P. Challenor, R. Lunn, S. Narendran, and S. Pollard. 2010. Flood perception and mitigation: The role of severity, agency, and experience in the purchase of flood protection, and the communication of flood information. Environment and Planning A: Economy and Space 42(12): 3023-3038.

Terpstra, T., M.K. Lindell, and J.M. Gutteling. 2009. Does communicating (flood) risk affect (flood) risk perceptions? Results of a quasi-experimental study. Risk Analysis 29(8): 1141-1155.

Tran, P., F. Marincioni, R. Shaw, M. Sarti, and L.V. An. 2008. Flood risk management in Central Viet Nam: Challenges and potentials. Natural Hazards 46(1): 119-138.

Tversky, A., and D. Kahneman. 1973. Availability: A heuristic for judging frequency and probability. Cognitive Psychology 5(2): 207-232.

Valeriano, O.C.S., T. Koike, D. Yang, C.T. Nyunt, D.V. Khand, and N.L. Chau. 2009. Flood simulation using different sources of rainfall in the Huong River, Vietnam/Simulation d'inondation à l'aide de différentes sources d'information pluviométrique dans le bassin de la Rivière Huong, Vietnam. Hydrological Sciences Journal 54(5): 909-917.

Valkengoed, A.M. van, and L. Steg. 2019. Meta-analyses of factors motivating climate change adaptation behaviour. Nature Climate Change 9(2): 158-163.

$\mathrm{Vu}, \mathrm{T} . \mathrm{T}$., and R. Ranzi. 2017. Flood risk assessment and coping capacity of floods in central Vietnam. Journal of HydroEnvironment Research 14: 44-60.

Ward, P.J., B. Jongman, S.F. Weiland, A. Bouwman, R. van Beek, M.F.P. Bierkens, W. Ligtvoet, and H.C. Winsemius. 2013. Assessing flood risk at the global scale: Model setup, results, and sensitivity. Environmental Research Letters 8(4). https://doi.org/ 10.1088/1748-9326/8/4/044019.

Weber, E., and C. Hsee. 1998. Cross-cultural differences in risk perception but simular attitudes toward perceived risk. Management Science 44(9): 1205-1217.

Weinstein, N.D. 1989. Effects of personal experience on selfprotective behavior. Psychological Bulletin 105(1): 31-50.

White, G.F. 1945. Human adjustment to floods: A geographical approach to the flood problem in the United States. University of Chicago. Department of Geography, Research Paper No. 29. Chicago, IL: University of Chicago.

Windham, G.O., E.I. Possey, P. Ross, and B. Spencer. 1977. Reactions to storm threat during hurricane Eloise. Social Science Research Center, Report 51. State College, MS: Mississippi State University.

Winsemius, H.C., L.P.H. van Beek, B. Jongman, P.J. Ward, and A. Bouwman. 2013. A framework for global river flood risk assessments. Hydrology and Earth System Sciences 17(5): $1871-1892$.

Wolf, J., W.N. Ader, I. Lorenzoni, V. Abrahamson, and R. Raine. 2010. Social capital, individual responses to heat waves and climate change adaptation: An empirical study of two UK cities. Global Environmental Change 20(1): 44-52.

World Bank. 2010. Weather the storm: Options for diaster risk financing in Vietnam. Washington, DC: World Bank.

Zheng, Y., and M. Dallimer. 2016. What motivates rural households to adapt to climate change? Climate and Development 8(2): $110-121$. 